\title{
Da Saúde Pública às Políticas Saudáveis - Saúde e Cidadania na Pós-modernidade
}

\author{
Antônio Ivo de Carvalho ${ }^{1}$
}

\begin{abstract}
Resumo: O artigo discute alternativas para o futuro da Saúde Pública, nos marcos do pensamento e das exigências da pós-modernidade. Apresenta os avanços sanitários alcançados na época moderna, e aborda os efeitos mórbidos da tecno-ciência. Com base nos aportes do pensamento pós-moderno, propõe uma agenda de desafios a serem enfrentados pela nova Saúde Pública. Especificamente, propõe novos aportes conceituais para lidar com as relações subjetivo-objetivo e coletivo-individual no campo sanitário. Discute, ainda, as condições e possibilidades de que a proposta de Políticas Saudáveis possa apontar para uma renovação da identidade da saúde pública.
\end{abstract}

Palavras-chave: Políticas Saudáveis; Saúde na Pós-modernidade; Crise da Saúde Pública.

Summary: This paper discusses alternatives for Public Health in the future, based on the ideas and demands of postmodernity. It presents the sanitary improvements achieved in modern times and discusses the morbid effects of techno-science. Based on the contributions of the post-modern thought, it proposes an agenda of challenges to be faced by the new Public Health. Moreover, it suggests new conceptual ways of dealing with subjective versus objective, and social versus individual relationships in the sanitary field. It discusses the premises and the possibilities for the Healthy Policies to become a new identity of public health.

Keywords: Healthy Policies; Health in Postmodernity; Crisis in Public Health.

\section{Introdução}

As transformações ocorridas no mundo contemporâneo, ao longo das três últimas décadas, têm sido de tamanha envergadura e têm se dado com tal velocidade que parecem colocar a humanidade no limiar de etapa singular de sua história. No campo da política e da economia, tais transformações têm sido chamadas de "globalização" e, no campo das ciências e da cultura, de "pós-modernidade".

As mudanças têm sido atribuídas a uma suposta crise da modernidade, entendida como um esgotamento ou enfraquecimento do iluminismo como matriz da cultura moderna.

' Núcleo de Estudos Político-Sociais em Saúde, Escola Nacional de Saúde Pública, Fundação Oswaldo Cruz, Rio de Janeiro 
Considera-se que a razão iluminista, impulsionadora do progresso, confiante na capacidade humana de construir um futuro sempre melhor, foi posta em xeque a partir dos anos 60/70, quando se evidenciaram os limites e perversidades do modelo de desenvolvimento baseado na dominação/exploração desenfreada da natureza e no antro-pocentrismo arrogante. O racionalismo extremado, obcecado com a objetividade, terminou por revelar-se incapaz de dar conta das complexidades de um mundo que a própria modernidade foi moldando, levando à perda da eficácia do discurso científico, à emergência de novas racionalidades e à legitimação de outras formas de conhecimento.

De maneira ainda imprecisa, mas já polêmica, vem sendo chamado de pós-moderno o discurso ou pensamento que emerge e, ao mesmo tempo, trata dessas transformações, relacionando-as à temática da sociectade pósindustrial. Acumulação flexível, difusão social da produção ("fábrica difusa"), fragmentação geográfica e social do processo de trabalho, terceirização, isolamento político da classe trabalhadora, "precarização" das relações de trabalho são categorias e temas introduzidos e discutidos por diversos autores (Bell, 1977; Lyotard, 1986; Harvey, 1993; Santos, 1994), para designar as transformações do mundo contemporâneo, matrizes de novos padrões culturais.

Tais transformações impactam, de maneira significativa, o campo da saúde, seja ao nível de seu objeto - o processo saúde-enfermidade de indivíduos e coletividades seja ao nível do instrumental teórico-metodológico em que se apóiam o conhecer e o fazer sanitário. Especificamente, na área da saúde pública, entendida como "o conjunto de práticas e conhecimentos organizados institucionalmente em uma sociedade, capazes de assegurar as condições necessárias à manutenção e reprodução da vida humana saudável" (Sabroza, 1994), são visíveis os sinais de uma crise em que o discurso sanitário vigente, caudatário do modelo biomédico, e as práti- cas a ele conexas parecem incapazes de enfrentar eficazmente a complexidade do quadro epidemiológico e sanitário emergente neste final de século.

Pretende-se aqui desenvolver algumas reflexões sobre o futuro da saúde pública, à luz da temática da pós-modernidade.

\section{Modernidade: Façanhas Sanitárias e Efeitos Mórbidos}

Pode-se dizer que o quadro contemporâneo da morbimortalidade humana, ou seja, a atual configuração quantitativa e qualitativa do processo de adoecer e morrer dos seres humanos, é fruto simultaneamente das façanhas sanitárias e dos efeitos mórbidos da tecno-ciência.

Já em meados da década de 70 , o epidemiologista americano Alan Dever (1976) coordenou um estudo pioneiro, cujos resultados documentam notavelmente essa nova realidade sanitária e, sobretudo, sinalizam a necessidade de novas bases conceituais para a explicação e intervenção no processo saúdedoença. Aplicando o modelo de "campo de saúde" proposto por Laframboise (1973), posteriormente utilizado para a reformulação da política de saúde canadense, Dever trabalhou com dados relativos ao estado da Geórgia e aos Estados Unidos como um todo. Tal modelo, concebido como alternativa à tradição explicativa microbiológica/ecológica, sustenta que a saúde é determinada por um conjunto de fatores agrupáveis em quatro divisões ou categorias: biologia humana, ambiente, estilos de vida e serviços de saúde. O componente biologia humana envolve a herança genética, o processo de maturidade (envelhecimento) e os assim denominados sistemas internos complexos. O ambiente é o componente que agrupa os fatores externos ao corpo, sobre os quais o indivíduo exerce pouco ou nenhum controle, envolvendo as dimensões física, social e psicológica. O estilo de 
vida é conceituado como o conjunto das condições que implicam na decisão ou controle do indivíduo: são os chamados riscos autocriados, ligados às atividades de lazer, ao padrão de consumo e às situações ocupacionais (trabalho). E, finalmente, o componente serviços de saúde que, lidando com as ações de prevenção, cura e recuperação da saúde, envolve a disponibilidade, qualidade e quantidade de recursos (bens e serviços) destinados aos cuidados com a saúde.

Trabalhando com taxas específicas de mortalidade por doença e por grupo etário, Dever relacionou as principais causas de morte com cada um dos quatro componentes do campo de saúde, estabelecendo assim a contribuição de cada um deles para a mortalidade geral da população. Encontrou os seguintes resultados, em ordem decrescente: estilo de vida (43\%), biologia humana (27\%), ambiente (19\%) e serviços de saúde (11\%). Para os mesmos componentes encontrou as seguintes proporções de gasto federal em saúde: estilo de vida (1,2\%), biologia (7\%), ambiente $(1,5 \%)$ e serviços de saúde (91\%).

A primeira série de proporções sugere o novo arranjo e a nova hierarquia de fatores que influenciam a configuração contemporânea da morbimortalidade humana, certamente muito distinta daquela de 50 ou 100 anos atrás. A segunda série revela as prioridades e direcionamentos da política terapêutica naquele momento. O descompasso entre ambas salta aos olhos.

Malgrado as restrições metodológicas de que possa ser objeto, o trabalho é bastante eloqüente ao apontar a emergência de uma nova realidade sanitária e explicitar seus nexos causais, positivos e negativos, com os fatores e processos da modernidade.

De um lado, são notáveis os êxitos da tecno-ciência e da modernidade na preservação e no prolongamento da vida humana. Nos últimos quarenta anos a esperança de vida ao nascer aumentou mais que durante toda a história da humanidade (Banco Mundial,
1993). Entre 1950 e 1990, enquanto a população mundial passou de 2,5 bilhôes para 5,3 bilhões de pessoas, a esperança de vida ao nascer pulou de 40 para 63 anos. A modernidade, certamente, proporcionou incontestáveis avanços quanto à competência tecnológica necessária à busca da saúde, seja no campo propriamente médico (diagnóstico e terapêutica), seja em outros campos (informação, educação, alimentação etc.). Os avanços no combate às doenças infecciosas, assim como a ampliação do acesso a bens e serviços de proteção social em geral e sanitária em particular, expressam a disponibilização, em larga escala, de tecnologias de alto impacto sanitário, como vacinas, métodos anti-conceptivos, saneamento, tecnologias educacionais, etc.

$O$ fato de que os valores mencionados sejam médias, que ocultam as enormes desigualdades prevalecentes no mundo, permite supor que é ainda possível teoricamente alcançar resultados melhores quanto ao prolongamento da vida, sem entrar no mérito da questão do limite biológico, a partir da universalização do acesso aos benefícios da ciência e da modernidade.

Por outro lado, a situação que emerge desses avanços vem configurando uma realidade sanitária nova e muito mais complexa. O prolongamento da vida, com o conseqüente aumento da idade média da população, traz em si novos problemas sanitários. De um lado, produz de imediato um aumento dos eventos/ doenças de natureza crônico-degenerativa, próprios do processo natural de envelhecimento biológico. De outro, provoca, em termos mediatos, um aumento da exposição aos fatores e situações patogênicas típicos das vertiginosas transformações sociais e culturais ocorridas na sociedade humana na modernidade, fortemente marcadas pela (oni)presença da tecno-ciência - industrialização, urbanização etc. São os agravos de natureza social, como a violência, o uso de drogas e grande parte dos distúrbios mentais, assim como aqueles decorrentes do contato ou consumo de produtos 
químicos ou físicos próprios dos grandes aglomerados urbano-industriais.

No caso do Brasil atual, só para citar um exemplo, cerca de $60 \%$ clos óbitos (1988) são provocados pelos grandes grupos das doenças cardiovasculares, das neoplasias e das causas externas. Esse mesmo grupo de agravos, em 1930, não era responsável por mais do que $16 \%$ das mortes. As doenças infecciosas, ao contrário, tiveram sua importância na mortalidade reduzida de 45 para 7\% no mesmo período (Duchiade, 1995).

Como já era apontado no estudo de Dever, as categorias "estilos de vida" e "ambiente" agrupam precisamente aquilo que chamamos efeitos mórbidos da civilização, não mais redutiveis a agentes ou fatores causais, sequer a redes de causaliclade claramente clelimitadas. Trata-se, antes, de um complexo mórbiclo, onde causals e efeitos se confundem e se sintetizam num "certo modo de andar a vida". Alimentaçìo, stress, poluiçào, esgarçamento social (sóciopatias), violência, sedentarismo apresentam-se como ingredientes indissociáveis dos marcos culturais e sociais onde se inscrevem. Mais do que fatores de risco, trata-se de situaçoes complexas onde o risco nào é mais externo a indivíduo, mas se inscreve, com ele, num complexo único de múltiplas dimensòes - biológica, social e cultural. Nem esse complexo é externo ao indivíduo, de modo que ele possa se proteger dos "fatores de risco" nele contidos, nem o indivíduo é mero portador de uma normatividade vital ou biológica a protegê-lo contra "agressões externas".

Kadt \& Tasca (1993) desenvolveram os conceitos de "chances de saúde" e "chances de vicla", na tentativa de qualificar essa nova complexidade do processo sanitário, e abrir caminho para novas abordagens terapêuticas voltadas não mais para o evitamento de fatores de risco isolados ou para o combate a seus efeitos, mas à promoção de situações mais favoráveis à saúde, integrando as diversas dimensões do processo, sobretudo as ambientais e sociais, num mesmo modelo de explicação e intervençào.

De qualquer forma, é bastante evidente o descompasso entre a política terapêutica atual e o quadro sanitário que ela deveria enfrentar. Embora o presente perfil epicle-miológico venha se delineando há algumas décadas, o modelo terapêutico, seja no campo da clínica, seja no da saúde pública, mantém-se preso ao antigo paradigma biomédico. Este, inclusive na sua versào mais completa, a ecológica, continua inspirando de modo hegemônico os modelos e as práticas de terapia contemporânea. Iń os agentes causadores dos agravos (biológicos, químicos, físicos), os hospecleiros ou vítimas desses agravos (mais ou menos suscetíveis a eles) e o meio (que favorece ou dificulta uma interaçào mórbicla). A intervençào terapêutica moderna, seja no âmbito da clínica, ou no da saúde pública, dirige-se sempre a um clesses fatores, em busca de evitar ou corrigir o desarranjo por ele provocado na economia do organismo humano.

$\mathrm{Na}$ verdade, as cluas vertentes principais de concepçào e explicação do normal e do patológico, a ontológica e a dinamista ou funcional, têm este ponto em comum: encaram a doença, ou melhor, a experiência de estar doente, como uma situação polêmica, quer omo a luta clo organismo contra um ser estranho, quer como uma luta interna de forças que se defrontam (Canguilhem, 1990).

Apesar do exponencial avanço da tecnociência e da parafernália terapêutica dele decorrente, parece cada vez mais existir uma impotencia cliante dos novos agravos e uma dificuldade em instrumentalizar políticas de intervenção adequadas, seja no processo de produção das situações de risco, seja na lógica da distribuição de seus efeitos sobre os indivíduos e coletividades.

É notório o esvaziamento das abordagens terapêuticas baseadas na metáfora, oriunda da tecno-ciência, do organismo humano como máquina, cujo funcionamento é preciso garantir através da correção de defeitos provo- 
cados por fatores, tanto externos como internos. A idéia da saúcle como ausência de doença e distância da morte tampouco é capaz de dar conta do complexo processo sanitário atual. Este, não sendo redutível a modelos causais simples, de corte biologicista, faz com que a saúde pública se torne cada vez mais dependente de saberes e decisões extrasetoriais. A clínica, por sua vez, passa a depender de tecnologias diagnósticas e terapêuticas cada vez mais sofisticadas e caras, em função também da complexidade dos agravos emergentes, sejam os crônicos (insuficiências funcionais), sejam os agudos (trauma). De certa forma, a saúde pública se vê paralisada e esvaziada, enquanto a clínica se elitiza.

Os números do trabalho de Dever mostram a tendência do atual modelo em gastar mais com atividades de cobertura e efetividade proporcionalmente menores. É claro que não se trata de imaginar uma transposição mecânica das proporçōes relativas a fatores causais para rubricas de gastos. Uma vacina custa menos que uma angioplastia. Não se trata tampouco de reproduzir o antigo coro da medicina preventiva contra a curativa. Mas o fato é que o atual perfil de gastos não dá conta de enfrentar com efetividade os problemas atuais de saúde. O caso dos serviços de emergência é típico. Não há possibilidade técnica, nem financeira, de construir prontos-socorros ou serviços de neurocirurgia que possam fazer frente ao vertiginoso e multifacético aumento da violência urbana. No município do Rio de Janeiro, por exemplo, $70 \%$ dos gastos da Secretaria de Saúde são consumidos nos serviços de emergência.

$\mathrm{Na}$ verdade, o quadro epidemiológico atual exige um modelo explicativo e terapêutico que pense os indivíduos diante da doença e da morte como o que de fato são: sujeitos sociais lidando com os resultados de suas escolhas e de sua intervenção, fruto de sua competência reformadora da vida natural, à qual deverão recorrer para enfrentar os desafios ora postos. Tais desafios não se situam mais somente no enfrentamento dos riscos de adoecer e morrer, mas sim em (con)viver com o mal-estar e as limitações cotidianas impostas pelos novos agravos. Em outros termos, importa cada vez mais não apenas a duração ou quantidade de vida, mas a maneira como ela é vivida, ou seja sua qualidade (Reichenreim \& Werneck, 1994).

Essas novas exigências de integração conceitual e prática das diversas dimensões do processo de produção e distribuição dos problemas de saúde remetem, certamente, à construção de uma nova racionalidade sanitária.

\section{Pós-modernidade e Saúde Pública: Desafios Conceituais e Práticos}

Talvez a pós-modernidade na saúde pública comece em fins da década de 70, com a frustrada campanha mundial pela erradicação da malária. Após um verdadeiro esforço de guerra e alguns bilhões de dólares, a campanha resultou num retumbante fracasso e, pior, num agravamento do problema, graças à resistência ao DDT e aos quimioterápicos. Em 1975, a incidência mundial da malária era duas e meia vezes a de 1961, quando a campanha estava no seu auge (Garrett, 1995).

Embora tal episódio tenha permanecido à sombra, em função da vitória sanitária representada pela assim denominada "revolução imunológica" que, naquela década, ampliou de 5 para $80 \%$ a cobertura vacinal em menores de um ano, ele simboliza, mais do que um revés prático, o desmoronamento de um dos pilares do pensamento moderno: a crença nas possibilidades ilimitadas da ciência em controlar a natureza e vencer a doença.

Começa a ser questionado o conceito otimista de "transição da saúde", que qualificava as mudanças demográficas e epidemiológicas decorrentes dos novos padrões, declinantes, das taxas de fecundidade e mortalidade, em decorrência precisamente dos êxitos da tecno-ciência, como um caminho 
regular e previsível em direção a melhores níveis de saúde.

Fatos posteriores, como o advento das chamadas doenças infecciosas emergentes $e$ re-emergentes, assim como os limites políticos e econômicos à proposta de equalização das oportunidades de saúde, foram revelando um curso distinto para a história sanitária, sem muitas garantias de final feliz.

Hoje, a icléia de transição na saúde ou transição sanitária é associada muito mais à complexidade e à incerteza, e deve ser desdobrada em pelo menos três transiçôes: a demográfica, a da mortalidade e a da morbidade, seguindo dinâmicas próprias e interagindo segundo padròes complexos, onde incidem processos naturais e sociais, nào apreensíveis através de modelos simples de análise (Possas \& Marques, 1994).

$\mathrm{Na}$ verdade, a crença de que se vive um momento transicional na saúde firma-se cada vez mais, enquanto permanece obscura a direcionalidade e o sentido de tal processo. Para que a saúde pública seja capaz de enfrentar tais desafios, impôe-se, nào uma mera atualizaçào de conhecimentos técnicos ou de compromissos sociais, mas a convocação de uma empreitada intelectual que logre ultrapassar as limitaçôes da saúde pública "normal", empregando um pouco abusivamente a expressão kuhniana, e caminhar rumo à edificação de um novo paradigma sanitário.

Na sua relaçào com a ciência, ou como atividade científica, trata-se nào tanto de acurar instrumentos que permitam mensurar as coisas de forma mais precisa (ocorrências, agravos, microorganismos), ou prever tendências (probabilidades, cenários), mas sim de buscar aproximações compreensivas, transdiciplinares, com o objeto saúde, elucidando as relaçôes naturais e sociais nele embutidas.

$\mathrm{Na}$ sua relação com o social, ou como prática social, trata-se de ultrapassar as prescriçôes normativas, retóricas, impotentes contra as desigualdades sociais e de saúde, e assumir abordagens que, interdisciplinares no conteúdo e intersetoriais na ação, mobilizem os recursos cognitivos e materiais necessários a seu novo escopo.

Entretanto, tal busca não poderá se dar fora do clima cultural "mudancista" que vem se fixando e expandindo neste fim-de-século. O pós-moderno, seja como radicalização da modernidade revolucionária, ou como seu contraponto reacionário, aporta ao debate contemporâneo um conjunto de contribuições e questionamentos que não convém desdenhar.

Não há, na verdade, um paradigma de pensamento pós-moderno, pensamento que, por sinal, prefere despojar-se das pretensões de universalidade e objetividade dos modernos. Deve ele, antes, ser visto como uma construçào, uma transição paradigmática que envolve desafios. Santos (1995), para ilustrar essa busca, apresenta quatro teses:

- Todo o conbecimento científico-natural é científico-social, expressando com isso nào só a superação da dicotomia entre as ciências naturais e as ciências sociais, mas o fato de que ela se dá sob a égide ou hegemonia das ciências sociais;

- Todo o conbecimento é local e total, com isso designando que a fragmentaçào disciplinar característica da ciência moderna é substituída pela fragmentação temática da ciência pós-moderna;

- Todo o conbecimento é auto-conhecimento, mostrando assim a emergência de um conhecimento compreensivo e íntimo que nào nos separa e antes nos une pessoalmente ao que estudamos, assumindo que o "objeto é a continuação do sujeito por outros meios";

- Todo o conbecimento visa constituir-se em senso comım, para mostrar que, ao contrário da ciência moderna, que se constituiu contra o senso comum, considerado superficial, ilusório e falso, a ciência pós-moderna procura reabilitar o senso comum, reconhecendo nele virtualidades para enriquecer nossa relação com o mundo. 
Fugiria completamente ao escopo e mesmo ao fôlego do presente trabalho discutir todas as implicaçôes do pensamento pósmoderno para o campo da saúde pública. Entretanto, ensaiaremos aqui algumas reflexôes a respeito de dois deslocamentos operados pelo pensamento pós-moderno, cujos impactos no campo do pensamento sanitário podem ser de grande valia.

Trata-se do deslocamento do "objetivo" para o "subjetivo" e clo "coletivo" para o "individual". Presentes em toda a evoluçào conceitual e prática do campo da saúde pública, esses dois pares de categorias estào hoje a exigir um novo ponto de equilíbrio nas suas relaçôes, de forma a atender às novas exigências postas pela crise.

\section{Relação Objetivo/Subjetivo}

Sem pretensões de criar uma periodizaçào ou uma taxonomia, é possível verificar que a relaçâo objetivo/subjetivo no campo da saúde pública sofreu alteraçôes ao longo do tempo, podendo ser identificados pelo menos três padrōes principais que, em linhas gerais, se sucederam cronologicamente, mas que até hoje convivem. O primeiro corresponde à saúde pública tradicional, constituída à imagem e semelhança da tecno-ciência e do modelo biomédico. O segundo resulta da influência do pensamento social, principalmente em sua vertente estruturalista histórica, sobre o pensamento biomédico, constituindo propriamente o campo da saúde coletiva. O terceiro representa o esforço das ciências sociais em disputar com as ciências naturais a primazia do conhecimento sobre o objeto saúde.

A saúcle pública moderna, hoje considerada tradicional, nasce sob a égide do pensamento positivo, lidando com a "objetividade" dos modelos de explicaçào do processo saúde-doença. Desde a medicina social anglosaxônica, em luta contra os miasmas, até a saúde pública francesa pasteuriana, às voltas com os micróbios, as práticas sanitárias fundaram-se na objetividade do saber científico. No início deste século, sob a inspiraçào da obsessào anti-microbiana, políticas e práticas de saúde pública disseminaram-se através do paradigma "campanhista" de organizaçào sanitária. Sob a lógica do modelo biológico/ecológico que estabelecia nexos causais na cadeia agente/hospedeiro/meio, tratava-se de implementar políticas e açôes voltadlas para a interrupçâo do ciclo material de transmissào, agindo sobre qualquer un de seus estágios, inclusive o homem, seja como doente, seja como hospedeiro. O homem era o objeto de uma açào sanitária que nâo tinha sujeitos, mas agentes técnicos portadores de um conhecimento técnico positivo, tornado norma sanitária a ser seguida por todos. Soberana na sua positividade e na sua autoridade técnica, a saúde pública submetia tudo e todos às suas prescriçoes.

É curioso observar que neste paradigma de organizaçào sanitária a saúde pública terminou tendo de lidar com subjetividades de oposiçào, explicitadas na resistência popular às medidas sanitárias compulsórias, como as vacinas, borrifaçôes etc.

O segundo padrào, o da saúde coletiva, representa o primeiro momento de incorporação do social aos cânones do pensamento sanitário, o que ocorreu a partir dos anos 60. Primeiro como "variável" influente na distribuiçào de riscos e agravos entre as pessoas, depois incorporando-se ao modelo de explicaçào do processo saúde-enfermidade. É quando se desnaturaliza o conceito de "história natural das doenças", introduzindo-se o social como poderoso diferencial de riscos sanitários, associando-os à fragilidade e aos riscos sociais.

No plano das práticas, é dessa época e com base nessa concepção mais complexa do processo saúde-enfermidade, que a saúde pública, rebatizada como saúde coletiva, consagra sua inserçào definitiva no plano das políticas sociais. Aproxima-se das idéias de cidadania e de democracia, consolidando seus compromissos com a universalidade e a eqüi- 
dade, e ganha em dimensão polítca, incorporando a seu arsenal de práticas terapêuticas a ação social ou política.

No que dir respeito à questào objetivo/ subjetivo, a entrada do social, a despeito de enriquecer o modelo explicativo, altera pouco sua positividade, já que a realidade, embora constituída e conformada com a interveniência do social, uma vez estabelecicla, permanece como um molde objetivo, em um modelo onde as pessoas e coletividades estariam submetidas a riscos externos a clas. Ou seja, no que diz respeito à gênese das doenças, as realidades permaneciam, embora socialmente determinadas, redutiveis à objetividade de fatores de risco à saúde.

$\Lambda$ subjetividade, neste modelo, é assumida ao nível dos sujeitos que se constituem ná açào social dirigicla a remover ou neutralizar os fatores sociais geradores do fato sanitário "objetivo". É conhecido aqui o preclomínio da trádição marxista ou estruturalista histórica, cuja vertente italiana cunhou a noçào de "consciência sanitária", para designar a apropriaçào do conhecimento técnico acerca da história "social" da doenças e da seletividade social dos riscos sanitários, como requisito para a constituição de sujeitos sociais e políticos e, portanto, de agentes de transformaçào.

A subjetividade aqui admitida é aquela que brota da necessidade coletiva e que se organiza em sujeitos coletivos - no Estado, no partido, nas organizações classistas e comunitárias - portadores de projetos políticos de intervenção/interação nas estruturas que moldam socialmente as realidacles sanitárias.

Essa matriz de pensamento social, filiada às correntes estruturalistas e deterministas, estaria referida à vertente das ciências sociais "mais diretamente vinculada à epistemologia e à metodologia positivistas das ciências naturais", segundo a classificação proposta por Santos (1994).

A outra vertente, segundo o autor, "de vocação anti-positivista, caldeada numa tradição filosófica complexa, fenomenológica, interacionista, mito-simbólica, hermenêutica, existencialista, pragmática", teria desempenhado um papel matricial na marca pós-moderna do paradigma emergente, aportando, só posteriormente, sua contribuição ao campo sanitário, quando entào fixa o já mencionado terceiro padrào de relaçìo objetivo/subjetivo.

Situam-se, neste terceiro padrào, as críticas alos cleitos mórbidos da modernidade e da medicina tecnológica feitas já clescle os anos 60. Denunciando a morbiclade autoprovocada pela sociedade humana através da tecnociência, os assim denominados "movimentos contraculturais" de entào atribuíam esses efeitos a um excesso de intervençào humana no natural, a uma espécie de excesso de ciência. Illich (1975) foi um dos expoentes do movimento de denúncia da iatrogenia do modelo biomédico, chegando a cunlar o conceito de "contra-produtividade social", para designar o fenômeno de que "quanto mais ação medicalizada pela saúde, menos saúde".

Analogamente aos movimentos operários que se voltaram contra as máquinas para resistir à tecnificação do trabalho, tal postura termina por reificar a ciência e reduzi-la a seus efeitos indesejáveis, num certo "naturismo" que implica em abrir mào da autoria humana da ciência. Embora expressiva de um estado de espírito próprio de toda uma época e testemunha da perda progressiva de prestígio da ciência como caminho retilíneo e irreversível para o progresso, tal corrente não logrou um porte conceitual suficiente para se firmar. Permaneceu marginal, às vezes folclórica, alimentando um discurso extremado e defensivo em relação à ciência como instrumento da competência humana de reformar a vida.

Entretanto, em relação ao padrão anterior, representa um avanço, ao criticar a essência do modelo biomédico e suas conexões com o complexo urbano-industrial. Ou seja, ataca a tecno-ciência, nào porque seus frutos seriam socialmente mal distribuídos ou inacessíveis, mas por serem ineficazes, enganadores e morbogênicos. 
O seu amadurecimento leva ao aparecimento do "construcionismo", corrente da antropologia social que se desenvolve no campo da saúde e da medicina, e expressa o descontentamento e a decepção com as prerrogativas de objetividade e de universalidade reivindicadas pelo pensamento científico e, assim, pelo modelo sanitário biomédico. Aparece assim como "guardiã de um tesouro de saberes desprezados ou destruídos por uma modernidade arrogante que se julgava detentora da verdade" (Carrara, 1994).

Aqui, a subjetividade é francamente dominante. A doença é destituída de objetividade e reduzida a mera invenção social, mera ideologia. Procura "mostrar de que maneira a medicina se origina do social e produz o social" (Herzlich apud Carrara, 1994). Declara que a medicina "não realiza a decodificação do orgânico ou da doença, mas sim a sua construção a partir de categorias cognitivas socialmente dadas que manipula".

Se o positivismo da saúde tradicional está claramente superado, nenhuma das duas abordagens sociais, nem a estruturalista nem a relativista, parecem aptas a fornecer um tratamento satisfatório da questão objetivo/subjetivo.

Parece claro que a complexidade do quadro sanitário emergente situa-se além das possibilidades explicativas de qualquer dos três padrões mencionados:

- Nem a saúde pública tradicional ou positiva, para quem tudo se reduz ao biológico;

- Nem a saúde pública social-estrutural, para quem a subjetividade é moldada e aprisionada na estrutura;

- Nem a saúcle pública relativista, para quem a subjetividade é soberana e construtora do objeto saúde.

A chamada transição sanitária resulta de uma conjugação de fatores e situações biológicas, demográficas, sociais, culturais, econômicas e políticas que, dificilmente, será apreensível através das abordagens quantitativas clássicas, ou mesmo com aproximações qualitativas triviais. A AIDS ilustra, de maneira eloqüente, a imperiosa necessidade de conectar saberes da biologia, do social, do cultural, tanto para entendê-la, quanto para enfrentá-la.

A propósito exatamente da AIDS, Camargo Jr. (1994) observa criticamente o processo de construção de categorias diagnósticas na prática médica como uma combinação das "inflexíveis exigências do método científico com (...) toda uma gama de fatores sócio-culturais (...) 'não científicos'". Adverte para a ambigüidade da produção do saber e preconiza "uma relação mais crítica com as verdades da ciência", como forma de evitar o reducionismo e a instrumentalização.

O novo padrão de articulação entre o biológico e o social terá certamente de conceder uma primazia conceitual e metodológica à subjetividade que, entretanto, não poderá se restringir nem àquela de sujeitos engessados numa lógica coletiva estruturalmente definida, nem àquela de sujeitos que se constituem com a eliminação da objetividade.

Pode se dizer que, diante dos desafios da pós-modernidade, exige-se do campo da saúde pública que ele empreenda e supere a herança da relação dicotômica, conflituosa, entre objetividade e subjetividade, assumindo-se como um campo de interação, interseção de sujeitos em três territórios: um território social, onde se confirme o compromisso com a equalização de oportunidades de saúde, com a universalidade e com a eqüidade; um território cultural, onde se admita o caráter aproximado e construído das categorias relacionadas ao binômio saúde-enfermidade, sua dimensão simbólica e suas conexões com a experiência humana de estar no mundo; e um território propriamente natural, objetivo, material, onde um sujeito cognoscente se compreenda distinto de seu objeto "natural", guardando, porém, com ele, uma relação de intimidade e interação, de seu possível (re)criador. 


\section{Relação Coletivo/Individual}

É clássica a dicotomia coletivo/indivíduo no campo intelectual e prático da saúde. A tradição da medicina científica ou do modelo biomédico deixou o indivíduo a cargo da clínica e o coletivo a cargo da saúde pública. Foi por esta via que o social se incorporou, abrindo caminho para a consideração da subjetividade no âmbito do pensar e do fazer sanitário. Mas, como vimos, os sujeitos admitidos eram os coletivos, interagindo seja com realidades sociais, seja com realidades culturais.

A subjetividade na dimensão individual, ou a questão dos sujeitos individuais, aparece somente na clínica, com o advento das propedêuticas psicossomáticas e da consideraçào dos indivíduos como singularidades biopsíquicas.

É notável constatar que os progressos sanitários da modernidade ocorreram, em grande parte, a favor e pela ação das classes trabalhadoras que, como sujeitos políticos, fizeram-se sujeitos de direitos sociais, no processo de constituição e expansão da cidadania moderna.

Entretanto, a já mencionada crise da modernidade decorre também "da revolta da subjetividade contra a cidadania, da subjetividade pessoal e solidária contra a cidadania atomizante e estatizante" (Santos, 1994). O autor considera que "uma tensão entre uma subjetividade individual e individualista e uma cidadania direta ou indiretamente reguladora e estatizante percorre toda a modernidade". Discute também, de maneira bastante original, o paradoxo através do qual "os ganhos em cidadania converteram-se (por excesso de regulação) em perdas em subjetividade", sugerindo que a superação da tensão entre subjetividade e cidadania só poderá ocorrer no marco do princípio da emancipação, em lugar do marco, até aqui vigente, da regulação.

Outros autores sublinham o advento de um novo estatuto para o individual na tran- sição pós-moderna. Segundo Moriconi (1994), "a sociedade pós-industrial depende, para sobreviver, da informação, dos jogos entre indivíduos e de decisões tomadas a partir da simulaçāo de modelos, ao passo que a sociedade industrial depende de energia, do jogo contra a natureza, do empirismo e da experimentação". Diversos autores vêm desenvolvendo as chamadas teorias da ação social, em oposiçào às clássicas teorias sociais, também para realçar um crescente peso dos indivíduos e sua ação nos processos de transformação social (Elster, 1994).

Por outro lado, não é nova nas ciências sociais a idéia de que não é possível "um eı destituído de um nós" (Elias, 1994). Discutindo as alteraçōes e tendências contemporâneas na "balança nós-eu", Elias comenta que "a ascensão da humanidade no sentido de se tornar a 'unidade de sobrevivência' predominante marca um avanço da individualização". Considera essa tendência de individualização não como uma oposição ao coletivo universal ou solidário, mas como uma alternativa às limitações dos diversos coletivos como 'unidades de sobrevivência', ou seja, como locus de identificação com a possibilidade material e social de sobrevivência individual. Como se os Estados nacionais, que propiciaram a expansão dos direitos e da cidadania via regulação social, houvessem se tornado, no novo quadro mundial de integração e globalização, uma esfera tendencialmente insuficiente diante dos anseios descentralizadores e das demandas emancipatórias.

Pensar uma nova relação entre coletivo e indivíduo no campo da saúde envolve a discussão de pelo menos duas temáticas. A primeira diz respeito ao enfraquecimento do papel do Estado na mediação coletivo/indivíduo, com um novo fortalecimento do princípio rousseauniano da democracia comunitária (Santos, 1994). É o advento das organizaçôes e instituições da sociedade civil, de caráter não-lucrativo, cumprindo funções da esfera pública, fundando um novo campo de 
pensamento e práticas renovadoras das relaçōes intersubjetivas, com base na solidariedade social.

O segundo, que será aqui desenvolvido, diz respeito à emergência da questão ética que hoje perpassa todo o campo da saúde.

$\Lambda$ questáo ética incide diretamente sobre o próprio escopo e os objetivos da saúcle pública. Esta deve buscar táo somente prolongar a vida humana ou pretende igualmente melhorar sua qualidade? Diz respeito as coletividades, com suas regularidades e médias, ou visa aos indivíduos, com suas singuJaridades e diferenças? Por mais que o bom senso se apresse em optar por ambals, o quadro sanitário contemporâneo mostra que sào cada vez matis lreqüientes as situaçoes de conflito, a envolver escolhas, decisoes excludentes, tanto no plano dos espaços públicos/coletivos (alocaçao de recursos, legislaça, planificaçào social), quanto no plano das escollas cotidianas individuais.

Com a elevaçáo dos custos ocorrendo num ritmo mais rápido que a extensão dos benefícios sanitários, os recursos tecnológicos tendem a estar disponíveis/acessíveis a um número proporcionalmente menor de pessoas, num quadro de aumento global da demanda. No plano individual, as escolhas tratam de uma temática sanitária que, como se viu, envolve uma jurisclição interpessoal que demanda posturas e opcòes morais, seja nas relaçoes com o coletivo social, seja nas relaçòes com outros indivíduos.

Pode se dizer que, nessas escolhas, ocorre o encontro do debate sanitário com o clebate ético: a tensào entre a sacralidade e a qualidade da vida. O tradicional Princípio da Sacralidade dá Vida (PSV), norma absoluta com origens na moral cristà e, em parte, na ética médica hipocrática, tem presidido historicamente, e servido como arcabouço ideológico e ético, a uma medicina centrada no médico, voltada para cumprir "os processos teleológicos da ordem natural", tendo por dever absoluto conservar a vida contra aqui- lo que é contrário a essa ordem. A diversidade e a complexidade das sociedades modernas tem tornado obsoleto ou insuliciente o PSV e vem crianclo a "exigência de individualizar novas hierarquias de deveres, ou seja, reajustar uma nova 'tábua de valores' e estabelecer qual é o papel da autonomia com relação aos outros princípios (justiça, benevolência etc.)" (Mori, 1994). Trata-se do pluralismo ético que, em oposiça à rigidez de uma ética unicista, excessivamente normativa, accita e se ocupa clo "problema de como conseguir conciliar os diversos valores numa sociedade pacífica" (Iclem).

Num raciocínio analógico, é possivel identificar, na medicina e na saúde pública, o PSV com as abordagens terapêticas dirigidas normativamente aos fatores de risco e doença, enquanto as exigências formulaclas pelo novo quadro epidemiológico deveriam ser parametrizadas pelo Princípio da Qualidade de Vida $(\mathrm{PQV})$, isto é, por uma postura mais pluralista e flexível, que incorpore a dimensáo da vontade e da autonomia do indivíduo.

O clebate ético na saúde pública benelicia-se da proposta de Schramm (1995), que defencle a complementaridade dos clois princípios, como a "única maneira de evitar tanto o integralismo religioso ou fundamentalismo que muitas vezes acaba por desrespeitar um direito presente e atual em nome de um direito futuro e potencial, como é o caso do direito do feto com relaçāo ao direito da mãe - quanto - relativismo secularizado e, às vezes, cínico, que acaba por consagrar a lei do mais forte $e$ a lifeboat ethics (ética do salve-se quem puder) baseada em uma qualidade meramente de consumo e de gozo pessoal (...)".

O desafio, portanto, é o de equacionar uma nova política terapêutica capaz de superar os modelos marcados por um verdade técnica e por uma referência ética unicista, onde aos indivíduos é reservado o papel de objetos ou meros coadjuvantes de um enredo "natural" e a quem cabe apenas cumprir prescriçôes técnicas e éticas. No seu lugar, deve 
ser desenvolvida uma visão pluralista em que, preliminarmente, seja respeitada a diversidade de escolhas e vontades, e onde as prescriçôes sociais decorram de diálogos e contratos intersubjetivos.

Ao contrário do que alguns possam sugerir ou preferir, a abordagem ética não prescincle nem elide a questão social, mas realça que o seu enfrentamento envolve julgamentos e escolhas morais concernentes a situaçôes e entes sociais concretos.

Observe-se que o clebate ético refere-se não só às situações de fronteira (eutanásia, suicídio assistido, contracepção, fertilização), mas igualmente a situações cotidianas (alocação de recursos, programação de oferta), já de há muito enfrentadas por abordagens tradicionais.

Tal debate vem alcançando a saúde pública em vários domínios. Em recente trabalho, Garrafa (1995) faz um inventário do que denomina de "a dimensão da ética em saúde pública", discutindo os vários aspectos do impacto do pensamento ético sobre os paradigmas da saúde pública, sobre a prática dos profissionais de saúde, o ensino médico e as políticas públicas.

A questão ética está posta hoje para a saúcle pública, seja no seu diálogo com a ciência ética de fronteira -, seja no seu diálogo com a questão social, a desigualdade e a pobreza - ética do cotidiano (Pessini, 1995).

O diálogo com a ciência tem na biologia molecular e nas biotecnologias o seu campo privilegiado de desenvolvimento. Aqui, os enormes avanços em engenharia genética e tecnologias reprodutivas, por exemplo, tem suscitado esperanças nas possibilidades inéditas e quase ilimitadas de avanços na competência terapêutica humana. Esperanças que convivem e têm de dialogar com as cautelas e temores de emergentes delírios eugenistas e possíveis desastres genéticos acidentais. O projeto de mapeamento do genoma humano é expressivo dessas esperanças e temores. Na sua grandiosidade planetária, o projeto que, desde 1988, é coordenado internacionalmen- te pela Organização do Genoma Humano (HUGO), envolve gastos da ordem de 2 bithōes de libras, sendo o maior programa científico desde o projeto Apollo, voltado para o pouso do homem na lua. Chamado de o Santo Graal da biologia contemporânea, esse projeto vê-se hoje obrigado a aplicar parte de seu orçamento no estudo das conseqüências sociais, éticas e jurídicas de seus resultados (Wilkie, 1994).

O diálogo com o social e o cotidiano diz respeito à tensão entre o princípio da autonomia e o da responsabilidade. É emblemático que os tópicos "estilos de vida" e "ambiente" englobem mais de $60 \%$ das influências sobre o perfil de mortalidade, no estudo já mencionado de Dever. Nào é possível acreditar que problemas como alcoolismo, tabagismo, consumo de drogas, padrão alimentar, violência urbana de várias naturezas etc. possam ser equacionados a partir de algum tipo de normatividade "externa" aos indivíduos. Da mesma forma, não é mais suficiente atribuir às "estruturas" a oni-responsabilidade, seja pelas desigualdades sociais, seja pelas situaçōes e hábitos mórbidos, e aguardar as soluções coletivas ou gerais. Não que seja dispensável, para a saúde pública, o exame e a consideração das cadeias causais e das relaçôes de determinação, em todos os níveis, dos fatos sanitários. Mas é que, ao fim e ao cabo, toda a ação sanitária envolve o protagonismo de sujeitos reais, sua vontade política e suas escolhas morais.

Schramm \& Schramm (1995) fazem um importante exercício ao discutir os compromissos e diretrizes do Sistema Único de Saúde no Brasil - integralidade, descentralização, participação, eqüidade - à luz dos princípios básicos da bioética de Engelhardt - autonomia, beneficiência, propriedade, autoridade - concluindo pela sua congruência ou compatibilidade, enquanto "ferramentas para a qualidade de vida". Entretanto, advertem que "tais princípios são tipos ideais, instrumentos de legitimação das exigências de qualidade de vida de sujeitos 
reais. Isso implica que eles devem encarnar-se em situações concretas e, portanto, que cada situação concreta é normalmente e a priori um caso único que deve ser avaliado na sua peculiaridade (...)".

Técnica e politicamente, fica cada vez mais difícil imaginar, nas sociedades pluralistas e laicas contemporâneas, mesmo aquelas submetidas a baixos padrões econômicos e sociais, uma saúde pública que não pressuponha os indivíduos como sujeitos sanitários e, assim, sujeitos éticos.

$\mathrm{Na}$ verdade, torna-se manifesta a insuficiência ou imprecisão da idéia da "saúde como direito de cidadania e dever do Estado", no sentido de que a busca da saúde envolve um processo que não se restringe ao acesso universal a bens e serviços de consumo individual ou coletivo, e cada vez mais se desenvolve no território das relações interpessoais, onde direitos e deveres recíprocos marcam as relações indivíduo/indivíduo e indivíduo/coletivo.

É claro que a dimensão do dever e da responsabilidade individual não passa por evocações moralistas, nem por programas educativos verticais, por mais bem intencionados que estes sejam. A ineficácia sanitária de uma pedagogia "bancária", por onde fluem unidirecionalmente normas técnicas a serem seguidas pelas pessoas, ainda que com respaldo legal, já há muito foi demonstrada, pelos antigos e inócuos programas de educação sanitária e higiene pessoal, nos marcos da saúde pública tradicional.

Da mesma forma, a constituição de sujeitos nào passa pela modelagem cle uma "consciência sanitária" que, apossando-se da lógica estrutural do processo sanitário, automaticamente autorize e desencadeie ações corretivas, de abrangência individual ou coletiva.

Baudrillard (1990) lembra que o turbilhão de imagens produzidas e veiculadas pelos meios de comunicação e propaganda moldam desejos e valores numa incrivel velocidade e num tempo extremamente volátil. Segundo esse autor, numa sociedade em que a produção de merca- dorias é substituída pela produção de signos e imagens, a razão é superada pelo impulso, pelo desejo, pela espontaneidade.

$\mathrm{Na}$ verdade, as recentes alterações ocorridas no que constituiria um "senso comum" sanitário, com a incorporação de valores progressistas como a defesa ambiental, os direitos do consumidor, as questões de gênero, talvez possam ser explicadas, não tanto por uma "conscientização" tradicional, mas por uma sutil combinação de democratização de informações/saberes e progresso moral, nos marcos de uma filosofia prática voltada para a revalorização da vida. Algo como um "salto gestáltico" que vislumbra e desencadeia, não novos estilos ou hábitos pessoais, mas novas atitudes de vida, baseadas na "existência de uma rede de sentimentos e crenças morais compartilhadas pelos indivíduos que integram a comunidade", estabelecida nào por submissão à norma legal (temor à punição), nem só por identificação com a maioria (busca de reconhecimento), mas por internalizaçào (valo-ração ética em si: faço embora pudesse não fazê-lo, e independentemente do que pensem de mim), como propõe Fonseca (1994).

Talvez seja o caso de prestar mais atenção ao sociólogo, doublé de filósofo, Francesco Alberoni (1991) quando, discutindo os processos geradores de modificações nos modos de pensar e agir das pessoas, descreve o que chama de "estado nascente" dos movimentos como aquilo que

"... começa com uma descoberta, uma revelação, uma nova perspectiva da realidade. Uma perspectiva compartilhada, exaltante que se enriquece e modifica em relação aos problemas do momento e da atividade comum. Até tornar-se doutrina, ideologia, enquanto no começo era apenas um olhar comovido, vibrante, a intuição repentina e perturbadora de que o mundo podia ser modificado (...). A história do movimento é a história desta elaboração, da edificação de estruturas sociais aptas a realizar um novo modo de viver, uma nova solidariedade". 
Para a saúde pública, dotar o individual de um novo estatuto significa, não apartá-lo do coletivo social onde se inscreve e molda, mas redescobri-lo em suas virtualidades de sujeito de mudanças, de si e do coletivo.

\section{Políticas Saudáveis: Caminho para uma Nova Saúde Pública?}

O esforço de renovação conceitual, metodológica e prática do campo da saúde pública vem já de algum tempo. Um de seus marcos institucionais foi a Conferência Internacional sobre Promoção da Saúde, realizada pela OMS, em novembro de 1986, no Canadá, que aprovou a chamada Carta de Ottawa para a Promoção da Saúde. Nessa ocasião, o conceito de promoção da saúde passa a ser considerado a espinha dorsal da nova saúde pública e é pela primeira vez definido em termos de políticas e estratégias. Representou um avanço em relação à retórica genérica da Conferência de Alma-Ata (1977), que estabelecera a consigna "Saúde para todos até o ano 2000", através da expansão da atenção primária.

Em linhas gerais, a Carta de Ottawa considera os limites do modelo sanitário de base médica e aponta para um modelo mais amplo e complexo que incorpora como determinantes da saúde "os fatores ambientais, sociais, políticos, econômicos, comportamentais, biológicos e médicos" (WHO, 1991). Reconhece, então, que as decisões políticas de outros setores têm uma contribuição crucial para a saúde; que os ambientes físicos e sociais são importantes para o estabelecimento das condições de saúde e como parâmetros para o comportamento sanitário; que a comunidade pode e deve desempenhar um papel fundamental nas açôes sanitárias; e que os serviços de saúde precisam ser reorientados.

Ainda em 1986, é criado o Projeto Healthy Cities, no âmbito do Escritório Europeu da Organização Mundial de Saúde (OMS), com a finalidade de aplicar e operacionalizar a estra- tégia de saúde para todos no nível local. Nasceu na esteira da nova realidade política européia, que conferiu maior autonomia política e administrativa às cidades. $\mathrm{O}$ projeto baseia-se no conceito de promoção à saúde e propõe-se a desenvolver "novos estilos de acionar, facilitar, mediar e construir novas parcerias e coalizões para a saúde". Para tanto, adota como propósito ou missão "construir um movimento por uma nova saúde pública nas cidades da Europa e fazer da saúde um tema ou assunto de todos ao nível de cidade". Fixam quatro objetivos ao nível de políticas: visibilidade para a saúde, mobilização e decisão política, mudança institucional e ação inovadora para a saúde. Em 1988, estabelece-se um plano qüinqüenal centrado em cinco eixos a serem focalizados sucessivamente, a saber:

- Eqüidade em saúde;

- Fortalecimento da ação comunitária;

- Desenvolvimento ambiental para a saúde;

- Reorientação dos serviços de saúde e da saúde pública;

- Políticas saudáveis para as cidades saudáveis.

Tendo se iniciado em janeiro de $1986 \mathrm{com}$ menos de dez cidades européias, o projeto experimentou um espetacular crescimento, recebendo adesões entusiasmadas e caminhando para se constituir em uma rede internacional que envolve centenas de cidades e dezenas de milhões de pessoas. De um projeto inicial tornou-se um movimento que representa a "herança da impressionante história da saúde pública e a antecipação de um renascimento da saúde pública que nos leve a proporcionar saúde para todos os povos no mundo" (WHO, 1991).

Em 1988, por ocasião da Segunda Conferência Internacional de Promoção da Saúde, realizada em Adelaide, Austrália, foi cunhado o termo "políticas públicas favoráveis à saúde", expressando a crença de que resultados sanitários significativos dependiam da interveniência 
de um conjunto de políticas públicas, cuja formulação deveria levar em conta o critério de saúde (Ferraz, 1993).

Parecia estar em marcha a constituição de um novo marco de referência para as tentativas de superação do modelo biomédico. Ferraz (1993) chama a atenção para a base conceitual da proposta "em muitos aspectos semelhante à abordagem da medicina e da epidemiologia social no Brasil (...), por exemplo no que concerne à importância da dimensão socio-política sobre a saúde de uma população e sobre a responsabilidade pública acerca das condições de vida e de saúde".

No Brasil, sobretudo a partir do início dos anos 90, quando se acelerou o processo de descentralização, desenvolveram-se diversas experiencias municipais inovadoras, em busca de novos modelos de organização das práticas sanitárias. Embora sob denominações diversas, pode-se dizer que tais experiências vêm se orientando por alguns dos marcos renovadores estabelecidos a partir de 1986.

Silva Jr. (1996) identifica três propostas de modelos alternativos, representadas pelas experiências desenvolvidas, respectivamente, em Pau da Lima, distrito de Salvador (Bahia), Curitiba (Paraná) e Campinas (São Paulo). Ao estudá-las e compará-las, o autor aponta para sua diversidade e, ao mesmo tempo, para sua convergência e complementaridade, enquanto esforços de constituição do novo paradigma sanitário.

A diversidade corre por conta das diferentes ênfases e estratégias com que estas propostas enfrentam aspectos do modelo biomédico dominante, decorrentes das histórias particulares e perfis político-técnicos dos grupos que as conduzem. As próprias expressões cunhadas para nomeá-las, a saber, Saídecidade, em Curitiba, km defesa da vida, em Campinas e Sistemas Locais de Salide/Distritos Sanitärios, em Pau da Lima/Salvador, revelam essas diferenças, assim como seus discursos contêm os viéses provenientes das realidades locais. Para alguns, a proposta de cidades. saudáveis estaria situa- da mais no campo do urbanismo, não tendo condições de contribuir para os dilemas da organização de serviços de saúde; para outros, uma efetiva integração de políticas públicas, sob o primado do critério da saúde, tornaria supérflua ou secundária a discussão sobre a organização da assistência, e assim por diante.

Entretanto, essas experiências, assim como muitas outras atualmente em curso no país, são claramente convergentes e até complementares no que diz respeito ao esforço de construção de um novo paradigma para a saúde pública. Correspondem, em termos práticos e teóri$\cos$, a tentativas de redefinição de dicotomias clássicas, como: político $\mathrm{x}$ técnico, social $\mathrm{x}$ natural/biológico, coletivo $\mathrm{x}$ individual, Estado $\mathrm{x}$ sociedacle, profissional $\mathrm{x}$ usuário, hoje $\mathrm{x}$ amanhã, saúde $\mathrm{x}$ doença, prevenção $\mathrm{x}$ assistência, e diversas outras. Mendes (1993), discutindo o processo social e técnico da mudança das práticas de saúde no âmbito de experiênciaspiloto de distritos sanitários, aponta para a emergência de um "paradigma de promoção da saúde", como designaçào do esforço de superação do "modelo clínico" de organização dessas práticas.

Por outro lado, a construção desse marco mais geral exige um esforço teórico específico que, examinando as rápidas transformaçōes do quadro sanitário e do clima cultural ocorridas nos últimos anos, procure inferir tendências e identificar desafios.

Como reflexão preliminar, podem ser identificadas duas tendências de pensamento que hoje pressionam a atualização da identidade da saúde pública, como campo de saber e prática. Emergem das realidades políticas, sociais, culturais e científicas contemporâneas, e apontam vetorialmente para desenvolvimentos distintos e alternativos do futuro da saúde pública.

O primeiro desses vetores diz respeito ao crescente peso da razão econômica sobre o território epistêmico da saúde pública. Melo \& Costa (1994), analisando o processo de formação de agenda dos organismos internacionais 
ligados à saúde (OMS, OPS e Banco Mundial), apontam uma mudança de paradigma conceitual ao longo dos anos 80 e início dos 90, através da substituição do paradigma da saíde príblica pelo paradigma da economia da saide.

Sob inspiração das prescrições contencionistas do Banco Mundial, nos marcos das políticas de ajuste estrutural, ganham peso os critérios de eficiência na definição de políticas e estratégias, em busca de termos mais favoráveis para a relação custo-efetividade. A saúde passa a ser tratada antes por suas relações com a economia, avaliada por valores de mercado e considerada componente, mais do que resultado, das propostas de "desenvolvimento sustentável", "transformação produtiva" etc.

Uma alteração nada sutil nos termos da clássica equação desenvolvimentista que, na década de 50, tanto pesou sobre as políticas sanitárias latino-americanas, ao defender a saúde humana como pré-requisito para o desenvolvimento econômico. Lá, o papel econômico da saúde referia-se ao fator trabalho, aqui refere-se diretamente ao fator capital, de imediato submetido à lógica econômica do mercado.

Ao estabelecer a "subordinação dos princípios de eqüidade aos de eficácia, efetividade e economia nos gastos públicos" (Melo \& Costa, 1994), a seletividade de clientelas e a focalização de programas passam a compor, no quadro de escassez de recursos, o centro da agenda de organismos internacionais e de seus caudatários nacionais.

Resultam daí políticas sanitárias minimalistas, empobrecidas em sua racionalidade técnica e amesquinhadas em seu compromisso social. A abordagem interdisciplinar é dispensada de sua missão de desvendar o complexo sanitário, e reduzida ao subalterno papel de justificar ações intersetoriais limitadas, "deslegitimando" a demanda espontânea por assistência e introduzindo cestas sanitárias básicas, como estratégia quase exclusiva de combate à pobreza. O objeto da saúde pública deixa de ser o coletivo humano, histórica e socialmente constituído, e se restringe ao coletivo dos socialmente excluídos. A conseqüência dramática é que o discurso sanitário abandona a crítica à "linha da pobreza", para se submeter aos limites por ela delimitados. Em vez de procurar deslocá-la, como parte da agenda sanitária, limita-se a enfrentar suas conseqüências, fazendo dos coletivos de excluídos, despojados de cidadania e identidade, alvos anônimos de cuidados sanitários padronizados.

O segundo vetor remete à importância crescente das atividades "individuais" de promoção da saúde e prevenção de doenças. A ampliação ou disseminação de informações relacionadas às situações de risco à saúde provocadas pelos fatores da "civilização" tem levado, não raramente, a apropriações reducionistas dos processos saúde-enfermidade contemporâneos e aberto espaço para fenômenos culturais relacionados a novas representações de saúde, doença, corpo, ambiente etc.

Economicamente nada inocentes, multiplicam-se os apelos materiais e simbólicos por mudanças nos estilos de vida, sempre entendidos na dimensão individual, como caminho para o prolongamento da juventude, para o afastamento da doença e para o adiamento da morte. "Pós-modernamente" autonomizados com relação a seus contextos de origem e livres de qualquer relação de determinação ou causação prévia, os hábitos saudáveis são vendidos, pelas artes do mercado e pelos ofícios de atentos mercadores, como eficazes caminhos para uma "saúde perfeita". Muito mais que um "culto ao corpo", a nova utopia vem se firmando como uma espécie de estética sanitária, interessada não tanto nas externalidades visíveis do corpo físico, mas nas suas virtualidades biológicas de ser saudável.

O corpo biológico, "hibridizado e resignificado" (Braz, 1996), passa a ser o território e o instrumento, já agora não tão naturais, de obtenção da saúde. Melhorar a saúde é melhorar a performance biológica indi- 
vidual. A receita inclui descle cândidos exercícios físicos e clietas balanceadas até duvidosas terapias dietéticas e energéticas (vitaminas, aminoácidos, enzimas, radicais livres, hormônios, produtos dermatológicos, irradiações); descle o uso arbitrário de tecnologias diagnósticas de alta acuiclade (ressonância magnética) ou de uso portátil (equipamentos miniaturizados de verificação de sinais vitais), até a busca de tecnologias de prediçào e manipulação genética; desde pequenas cirurgias estéticas até mutilações cirúrgicas preventivas. Busca-se nào mais a intervenção pontual - diagnóstica e terapêutica - no corpo biológico para enfrentar agravos específicos, mas a intervenção permanente, abrangente, que perseguiria pretensiosa, ou ilusoriamente, uma espécie de prevenção geral de doenças.

O resultado aqui é uma saúde pública "neohigienista", obcecada por um ideal de salubridade humana, não mais definida por referência a contaminações "externas", mas por referência a uma desejada perfeição ou pureza física alcançável pelo manejo biológico.

Certamente, foge aos limites deste trabalho uma exploração mais profunda dessas tendências extremas. Entretanto, é preciso registrar que, nas duas hipóteses, o desenvolvimento futuro da saúde pública implica em significativas restrições de seu campo de saberes e

\section{Referências bibliográficas}

ALBERONI, F. (1991) - Gênese: como se criam os mitos, os valores e as instituições da civilizaçào ocidental. Rio de Janeiro: Rocco.

BANCO MUNDIAL (1993) - Relatório sobre o desenvolvimento mundial 1993. Washington DC: Autor.

BAUDRILLARD, J. (1990) - A transparência do mal: ensaios sobre os fenômenos extremos. Campinas: Papirus Editora.

BELL, D. (1977) - O advento da sociedade pósindustrial. São Paulo: Cultrix.

BRAZ, M. (1996) - "Quem procura acha. Acha? práticas. Na verdade, ambas as tendências desfiguram a identidade da saúcle pública, despojando-a do universalismo de seu escopo e da qualificação social de seu objeto. A reforma do corpo social é substituída pela reforma do corpo biológico.

Nesse quadro, pode ser conveniente, tanto para o clebate acadêmico quanto para a disputa política, fixar um campo de reflexões e práticas que aponte para a renovação da saúde pública exatamente a partir, e para preservar, aquilo que foi seu significante histórico, embora nem sempre explícito: a idéia da saúde como bem público.

A proposta de "políticas saudáveis" pode contribuir para esse mister, não como modelo operacional de política, mas como um campo de referências conceituais e empíricas, ainda em construção, rejeitando claramente tanto o papel de biombo para políticas sanitárias minimalistas, quanto o de expressão institucional e normativa da obsessão com a saúde perfeita.

Tendo nascido para ampliar e não para restringir o campo da saúde pública, a noção de "políticas saudáveis", a despeito de ser veículo de conteúdos muito abertos e imprecisos, pode funcionar como uma espécie de código ou senha de identificação dos esforços, teóricos e empíricos, de renovação progressista da saúde pública.

O corpo resignificado na pós-modernidade: o diagnóstico genético do câncer de mama e suas representaçôes" (Projeto de tese de doutorado). Rio de Janeiro: Escola Nacional de Saúde Pública, Fundaçào Oswaldo Cruz, mimeo.

CAMARGO Jr., K.R. (1994) - As ciências da AIDS \& a AIDS das ciências. O discurso médico e a construçào da AIDS. Rio de Janeiro: ABIA/IMS-UERJ/ Relume Dumará.

CAMPOS, G.W.S. (1991) - A sanide píblica e a defesa da vida. São Paulo: Hucitec. 
CANGUILHEM G. (1990) - O normal e o patológico. Rio de Janeiro: Forense Universitária.

CARRARA, S. (1994) - Entre cientistas e bruxos. In: Minayo, M.C. \& Alves, P.C. (orgs.) - Saíde $e$ doença: "um olbar antropológico. Rio de Janeiro: Editora Fiocruz.

DEVER, G.F.A. (1976) - An epidemiological model for health policy analysis. Social Indicators Research 2:465.

DUCHIADE, M.P. (1995) - Populaçào brasileira: um retrato em movimento. In: Minayo, M.C. (org.) Os muitos Brasis: saúde e populaçào na década de 80. Rio de Janeiro: Hucitec/ABRASCO.

ELIAS, N. (1994) - A sociedade dos individuos. Rio de Janeiro: Jorge Zahar Editor.

ELSTER, J. (1994) - As peças e engrenagens das ciências sociais. Rio de Janeiro: Relume Dumará.

FERRAZ, S. T. (1993) - A pertinência da adoção da filosofia de cidades saudáveis no Brasil. Saride em Debate 41:45-49.

FONSECA, E. G. (1994) - Vicios priwados, benefícios puiblicos? São Paulo: Companhia das Letras.

GARRAFA, V. (1995) - A dimensaio da ética em satide puíblica. São Paulo: Faculdade de Saúde Pública/USP.

GARRETT, L. (1995) - A próxima peste. Rio de Janeiro: Nova Fronteira.

HARVEY, D. (1993) - A condiçào pós-moderna. Sào Paulo: Edições Loyola.

ILLICH, I. (1975) - A expropriação da saúde. Rio de Janeiro: Nova Fronteira.

KADT, E. \& TASCA, R. (1993) - Promovendo a equilidade: um novo enfoque com base no setor saíde. Sào Paulo/Salvador: Hucitec/Cooperação Italiana.

LAFRAMBOISE, H.L. (1973) - Health Policy: Breaking the Problem down in More Manageable Segments. Canadian Medical Association Journal 108:388-93

LYOTARD, J.F. (1986) - O pós-modemo. Rio de Janeiro: José Olimpio Editora.

MARQUES, M.B. (1995) - Doenças infecciosas emergentes no reino da complexidade: implicaçōes para as políticas científicas e tecnológicas. Cadernos de Salide Plíblica 11(3):361-388.

MELO, M.A.B.C. \& COSTA, N.R. (1994). Desenvolvimento sustentável, ajuste estrutural e política social: as estratégias da OMS/OPS e do Banco Mundial para a atenção à saúde. Planejamento $e$ Políticas Príblicas 11:49-108.

MENDES, E.V. (1993) - Distrito Sanitârio. O processo social de mudança das práticas sanitárias do Sistema Único de Salide. São Paulo: Hucitec/ABRASCO.

MORI, M. (1994) - A bioética: sua natureza e história. Humanidades 332-341.

MORICONI. I. (1994) - A provocaçào pós-moderna. Rio de Janeiro: Diadorim/UERJ.

PESSINI, L. (1995) - O desenvolvimento da bioética na América Latina. Sailde em Debate 47:57-66.

POSSAS, C. \& MARQUES, M.B. (1994) - Health Transitions and Complex Systems: a Challenge to Prediction? In: Disease in Evolution. Global Changes and Emergence of Infectious Diseases. Annals of the New York Academy of Sciences, Vol. 740.

REICHENHEIM, M.E. \& WERNECK, G.L. (1994) - Adoecer e morrer no Brasil dos anos 80: perspectivas de novas abordagens. In: Guimarães, R. \& Tavares, R. (orgs.) - Salide e sociedade no Brasil anos 80. Rio de Janeiro: Relume Dumará/ABRASCO/ IMS-UERJ.

SABROZA, P.C. (1994) - Saúde pública: procurando os limites da crise. Rio de Janeiro: ENSP/ FIOCRUZ, mimeo.

SANTOS, B.S. (1994) - Pela mào de Alice. O social e o político na pós-modernidade. Porto: Edições Afrontamento.

(1995) - Um discurso sobre as ciências.

Porto: Edições Afrontamento.

SCHRAMM, F.R. \& SCHRAMM, J.M.A. (1995) Vigilância e qualidade em saúde: uma questão de bioética em epiclemiologia. Salide em Debate 47:50-56.

SCHRAMM, F.R. (1995) - Vida: sacralidade ou qualidade? Atualidade em debate 34:44-51.

SILVA Jr., A.G. (1996) - Modelos tecno-assistenciais em saúde: o debate no campo da saúde coletiva. Tese de doutorado. Rio de Janeiro: Escola Nacional de Saúde Pública, Fundaçào Oswaldo Cruz, mimeo.

WHO (1991) - Healthy Cities Project: a Project becomes a Movement. Copenhagen: WHO Regional Office for Europe.

WILKIE, T. (1994) - Projeto Genoma Humano: um conbecimento perigoso. Rio de Janeiro: Jorge Zahar Editor. 